\title{
STUDIES OF TEMPERATURE-HUMIDITY CHARACTERISTICS OF THE GREENHOUSE CYBER-PHYSICAL SYSTEM
}

\author{
Andrii-Volodymyr Midyk, PhD student \\ Lviv Polytechnic National University, Ukraine; e-mail: andriy3119@gmail.com; \\ Olha Lysa, Ph.D., As.-Prof., \\ Lviv National Agrarian University, Ukraine
}

https://doi.org/10.23939/istcmtm2020.02.

Abstract. The main information parameters of the microclimate of greenhouse premises are substantiated, in particular: air temperature, relative humidity, illumination of greenhouse premises, soil temperature, soil humidity, the concentration of carbon dioxide. The cyber-physical system for vegetables' cultivation with the regulation of temperature-humidity-insolation regime contains three subsystems, namely the subsystem of temperature control, the subsystem of humidity control, and the subsystem of insolation control. Accordingly, each of them is equipped with a conjugated smart sensor and a smart actuator. As a result, the choice of smart sensors and their location in the greenhouse is considered. CPS's model has been performed and tested. To assess the uniformity of the temperature in the greenhouse and the points of the sensor's location, the temperature and humidity were measured previously. The defined set of their values were maintained while the CPS' operation. Insolation.

Key words: Cyber-physical system, Measurement, Microcontroller, Smart sensor, Smart actuator, Temperature, Humidity,

\section{Introduction}

Greenhouses are an important unit of the agricultural production cycle, independently of the weather. To cultivate effectively every plant variety in the greenhouse, it requires to maintain the particular microclimate. Each plant needs it is own temperaturehumidity-insolation optimum, which gives a high yield. Outside of such optimum, plant growth slows down, and at a double acceptable deviation from the optimum, it stops altogether. One of the ways to solve this problem, is to develop an automated control system for temperature, humidity, and insolation of the greenhouse by using the nowadays technologies for example the smart sensors and actuators.

\section{Disadvantages}

An important role in the greenhouse's plant cultivation seems to be the monitoring and controlling of the parameters of the microclimate. For example, the required accuracy of maintaining the set temperature should not exceed $\pm 1^{\circ} \mathrm{C}$. Also, according to the physiological characteristics of plant life, the maintained temperature should be consistent with the level of illumination. The Temperature-humidity regime is maintained by automatic heating, ventilation, irrigation, illumination changes, etc. It is determined by the power of heat sources, as well as the design and technological features of the greenhouse. Therefore, it is important to select the structural elements of the greenhouse especially while their combined operation. Active research to improve the latter is conducted in the direction of increasing the number of analyzed parameters of microclimatic conditions of greenhouses $[1,10]$, development and improvement of the element base, including sensors, which generates primary information about the microclimate [2-9], actuators, microcontrollers [11], and software development.

\section{The Goal of the Work}

The purpose of the work is to research improving the microclimate control system in the greenhouse by using modern microcontrollers and software, control and measuring devices, to analyze the microclimatic conditions in greenhouses, to define the acceptable error of temperature $\Delta \mathrm{t}_{\mathrm{c}}$ and relative humidity $\Delta \varphi_{\mathrm{c}}$, control.

\section{Analysis of Greenhouse's Microclimate}

\section{Control System. Choice of the Technical Means}

An important role in plant cultivation is provided by the processes of monitoring the microclimate parameters of the greenhouse. For example, the required accuracy of maintaining the temperature should not exceed $\pm 1^{\circ} \mathrm{C}$. Also, according to the physiological characteristics of plant life, the maintained temperature should be consistent with the level of illumination. The Temperature-humidity regime is maintained by automatic heating, ventilation, irrigation, shading, etc. It is determined by the power of heat sources, as well as the design and technological features of the greenhouse. Therefore, it is important to select correctly the structural elements of the greenhouse. To improve the operation of them, research has to be conducted in the direction of 
increasing the number of analyzed parameters of greenhouses' microclimatic conditions $[1,10]$, the development and improvement of the element base, including sensors, which produce primary information on the particular characteristics in the greenhouse [2-9], actuators, microcontrollers for their circuits [11]. Therefore, the urgent task is to analyze the microclimatic conditions in greenhouses, identify the smart sensors for greenhouse design with an optimal statistical error of temperature control $\Delta \mathrm{t}_{\mathrm{c}}$ and relative humidity $\Delta \varphi_{\mathrm{c}}$, which would not exceed $\pm 1{ }^{\circ} \mathrm{C}$ and $\pm 3.5 \%$ accordingly.

\subsection{Technical means of the Greenhouse's} microclimate control system

The principle of operation of the microclimate control system in the greenhouse is regulating the power, f.i. switching in and out, of the electrical equipment based on the processing of a set of different Mis readouts. Namely, the air-heating system has to switch up is started if the air temperature in the greenhouse is lower than set before; the soil-heating system is switching up if the soil temperature in the greenhouse is lower than the set; ventilation is switched up by opening the ventilation transoms if the temperature or humidity in the greenhouse is higher than specified; air exchange with the environment is stopped by closing the ventilation transoms; humidification system is started in case if he humidity in the greenhouse is lower than the set; curtains are opened to ensure the growth of plants, increasing the sunlighting if the illumination of plants in the greenhouse is lower than specified; curtains are closed to reduce the sun irradiating if illumination is higher than specified; irrigation occurs when the soil moisture in the greenhouse is lower than specified; system of providing air with carbon dioxide to accelerate photosynthesis is started if the concentration of carbon dioxide in the air in the greenhouse is lower than specified. Therefore, to ensure the operation of the microclimate control system in the greenhouse, it is necessary to select technical means of the automatic climate control system and optimally locate them in the greenhouse or nearby it. Besides, the characteristics of the external weather conditions and design parameters of the greenhouse have to be measured and analyzed.

To design a CPS for vegetable cultivation, the Arduino Uno board is applied. It can smoothly regulate temperature and humidity while maintaining sufficient accuracy of the supported parameters. The following sensors for CPS's needs were selected: in particular, temperature and humidity sensors (accordingly, DHT21/AM2301 and DHT22 that are the digital sensors of high accuracy equipped with capacitive humidity sensor and NTC thermistor), illumination sensor BH1750, soil temperature sensor DS18B20 and capacitive soil moisture sensor (not susceptible to corrosion and therefore independent of soil salinity), greenhouse gas contamination sensor MG-811 or MH-Z19B. The system based on the Arduino UNO board allows implementing MIs with microprocessor control, which also yields the electric engines. The functional scheme for microclimate control in greenhouses is demonstrated below (Fig. 1).

Temperature-humidity sensors that can be exploited together with Arduino, are of DHT11, DHT21, DHT22, and HTU21 types [2-3]. Digital temperature-humidity sensor DHT11 yields the capacitive humidity sensor and thermistor. Digital temperature-humidity DHT22 / AM2302 sensor yields the NTC thermistor. The latter differs from the DHT11 sensor by a higher accuracy. The digital temperature-humidity high-accuracy sensor DHT21 / AM2301 is connected to the single-wire interface. The protocol and connection scheme is identical to the DHT22 sensor. The HTU21 temperature-humidity sensor applies an appropriate chip with an I2C interface, which provides an accuracy of temperature measurements $\pm 0.05{ }^{\circ} \mathrm{C}$. The technical characteristics of these temperature and humidity sensors are given in Table 1. While using the DHT11 sensor with the Arduino board, we receive less accurate results comparing with other high-mentioned sensors. Therefore, the DHT21/AM2301 and DHT22 sensors have been chosen as elements of a CPS for vegetable cultivation.

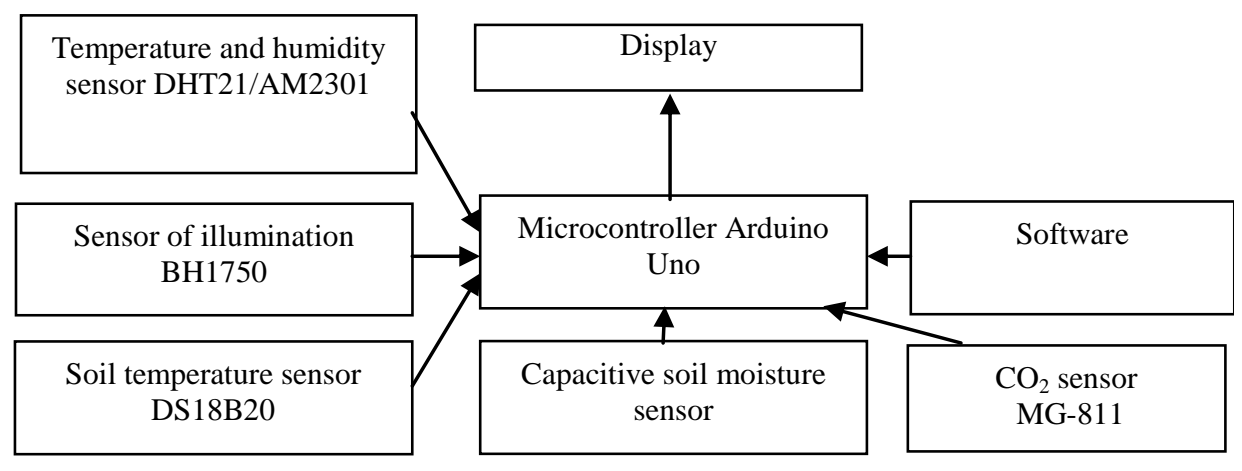

Fig. 1. Functional diagram for climate control in greenhouses 
Technical characteristics of temperature and humidity sensors

\begin{tabular}{|c|c|c|c|c|}
\hline Characteristic & DHT11 & DHT21/AM2301 & DHT22/AM2302 & HTU21 \\
\hline $\begin{array}{c}\text { Determination of } \\
\text { humidity }\end{array}$ & $\begin{array}{c}20-90 \% \\
\pm 5 \% \mathrm{RH}\end{array}$ & $\begin{array}{c}0-100 \% \\
\pm 3 \% \mathrm{RH}\end{array}$ & $0-100 \% \pm 2 \% \mathrm{RH}$ & $\begin{array}{c}0-80 \% \\
\pm 3 \% \mathrm{RH}\end{array}$ \\
\hline $\begin{array}{c}\text { Determination of } \\
\text { temperature }\end{array}$ & $\begin{array}{c}0-50{ }^{\circ} \mathrm{C} \\
\pm 2 \%(\max )\end{array}$ & $-40 \sim+80{ }^{\circ} \mathrm{C} \pm 0.5 \%$ & $\begin{array}{c}-40-+80{ }^{\circ} \mathrm{C} \pm 0.5 \\
{ }^{\circ} \mathrm{C}\end{array}$ & $\begin{array}{c}-10-+85^{\circ} \mathrm{C} \\
\pm 0.4^{\circ} \mathrm{C}(\max )\end{array}$ \\
\hline
\end{tabular}

To measure the illumination has been chosen a digital sensor GY-302 on BH1750 chip, which can work with a microcontroller according to the I2C protocol [4]. A photodiode is used as a light-sensing element. The measuring range is from 0 to 65535 lux (16 bits); the measured wavelength - $560 \mathrm{~nm}$; accuracy in the mode of high resolution is 1 lux; accuracy in the mode of low resolution is 4 lux; measurement period in highresolution mode is $120 \mathrm{~ms}$; measurement period in lowresolution mode is $16 \mathrm{~ms}$. Low current consumption and sleep function; filtering of light noise $50 / 60 \mathrm{~Hz}$; ability to select two-chip addresses for the I2C interface (one can connect two sensors to one bus at the same time, which allows distributing sensors in the room for a holistic measurement of light levels). The sensor does not require calibration that is convenient for the project.

To measure soil temperature, it is advisable to use a digital integrated sensor DS18B20 [5] with a unique factory-stitched 64-bit code that can be used by the microcontroller to communicate with a particular sensor on a common bus. Technical characteristics of DS18B20: interface - One-Wire; temperature range from $-55{ }^{\circ} \mathrm{C}$ to $+125{ }^{\circ} \mathrm{C}$; operating temperature - from 0 to $+60{ }^{\circ} \mathrm{C}$; measurement accuracy $-0.5{ }^{\circ} \mathrm{C}$; step of indications $-0.0625^{\circ} \mathrm{C}$. In the DS18B20 memory, one can store the boundary temperatures above which the sensor would alter the operation mode into alarm.

Soil moisture is measured by a YL-69 sensor with a built-in resistor of variable resistance [6]. However, the capacitive soil moisture sensor [7], unlike resistive moisture sensors, is not prone to corrosion. The output voltage is inversely proportional to soil moisture. The sensor is ideal for monitoring changes in soil moisture, for creating automatic irrigation systems for plants and for monitoring the integrity of the soil pipeline. We apply a capacitive sensor to determine soil moisture.

To measure the $\mathrm{CO}_{2}$-concentration in the Greenhouse is used eSense [10], which allows measuring the content in the ambient air in the range up to 10000 ppm and transmit data via analog output. You can also use the sensor of the infrared concentration meter $\mathrm{MH}$ Z19B, designed to quantify the content of carbon dioxide in the air [9]. The sensor operates with two output interfaces, temperature compensation, high linearity, and low power consumption [8].

\subsection{Study of temperature distribution and} relative humidity in the Greenhouse

To assess the uniformity of the temperature in the greenhouse and the choice of the location of the device sensors, which were used to study the characteristics of the process, measurements of temperature and humidity were carried out in a stabilized mode; measurements were performed with humidity and temperature sensors DHT11, DHT21/AM2301, DHT22 / AM2302 in the diagonal direction of the greenhouse every $4 \mathrm{~m}$ at a height of 1,2 and $3 \mathrm{~m}$. The interval between measurements was equal to one minute. The results are shown in Table 2.

The mean value is determined by the formula:

$$
\overline{\mathrm{x}}=\frac{1}{\mathrm{n}} \sum_{\mathrm{k}=1}^{\mathrm{n}} \mathrm{x}_{\mathrm{k}}
$$

Here $\mathrm{n}$ is the number of measurements; $\mathrm{x}_{\mathrm{k}}$ is the value of the $\mathrm{k}$-th measurement. The standard uncertainty of type $\mathrm{A}$ is defined by:

$$
\mathrm{u}_{A} \&=\sqrt{\frac{1}{\mathrm{n}-1} \sum_{\mathrm{k}=1}^{\mathrm{n}} \&_{\mathrm{k}}-\bar{x}^{2}}
$$

Similar measurements have been fulfilled with the help of the temperature-humidity sensor DHT11. Basing on the received data, it was argued that the DHT11 sensor is the worse than the DHT21 / AM2301 sensor. So, we have built the graphs based on measurements made with the help of the latter (Fig. 2).

Basing on the measurement results, the graphs of changes in temperature and relative humidity were constructed (Fig. 2-3). They demonstrate that the air parameters change within the greenhouse space. Towards the center of the greenhouse, the air temperature rises slightly and the humidity decreases. The temperature falling is accompanied by the increase in the relative humidity of the air near the walls due to the heat exchange with the environment. The significant temperature falling caused by heat leakage was fixed nearby the doors. The maximum temperature and the minimum humidity were recorded in the center of the greenhouse at a $3 \mathrm{~m}$ height. Therefore, this point $\mathrm{A}$ has 
been chosen for the installation of the measuring sensors at the height $\mathrm{Z}=2 \mathrm{~m}$. The obtained data give reasons to consider Greenhouse mathematically as an object with concentrated parameters.

Table 2

\section{Results of repeated measurements of air temperature at the height and length points of the greenhouse by the temperature-humidity DHT21/AM2301 sensor}

\begin{tabular}{|c|c|c|c|}
\hline \multirow{2}{*}{ Length, $\mathrm{m} \backslash$ Height, $\mathrm{m}$} & \multicolumn{3}{|c|}{ Air temperature in the greenhouse, $t^{0} \mathrm{C}$} \\
\hline & 1 & 2 & 3 \\
\hline 0 & 18.56 & 19.62 & 20.66 \\
\hline 0 & 18.55 & 19.61 & 20.68 \\
\hline 0 & 18.52 & 19.61 & 20.69 \\
\hline 0 & 18.49 & 19.57 & 20.69 \\
\hline 0 & 18.55 & 19.56 & 20.61 \\
\hline 0 & 18.51 & 19.61 & 20.66 \\
\hline Mean of multiple measurements, ${ }^{\circ} \mathrm{C}$ & 18.53 & 19.597 & 20.665 \\
\hline Standard type A uncertainty, ${ }^{\circ} \mathrm{C}$ & 0.01125 & 0.01022 & 0.01232 \\
\hline 4 & 19.08 & 19.83 & 21.73 \\
\hline 4 & 19.07 & 19.89 & 21.71 \\
\hline 4 & 19.05 & 19.86 & 21.73 \\
\hline 4 & 19.03 & 19.88 & 21.74 \\
\hline 4 & 19.1 & 19.86 & 21.7 \\
\hline 4 & 19.07 & 19.85 & 21.77 \\
\hline Mean of multiple measurements, ${ }^{\circ} \mathrm{C}$ & 19.06667 & 19.86167 & 21.73 \\
\hline Standard type A uncertainty, ${ }^{\circ} \mathrm{C}$ & 0.00999 & 0.00880 & 0.01010 \\
\hline 8 & 19.88 & 20.94 & 23.05 \\
\hline 8 & 19.87 & 20.93 & 23.09 \\
\hline 8 & 19.86 & 20.91 & 23.07 \\
\hline 8 & 19.83 & 20.93 & 23.09 \\
\hline 8 & 19.85 & 20.94 & 23.06 \\
\hline 8 & 19.86 & 20.94 & 23.05 \\
\hline Mean of multiple measurements, ${ }^{\circ} \mathrm{C}$ & 19.85833 & 20.93167 & 23.06833 \\
\hline Standard type A uncertainty, ${ }^{0} \mathrm{C}$ & 0.00703 & 0.00477 & 0.00749 \\
\hline 12 & 18.51 & 20.16 & 21.24 \\
\hline 12 & 18.52 & 20.15 & 21.22 \\
\hline 12 & 18.55 & 20.14 & 21.19 \\
\hline 12 & 18.57 & 20.13 & 21.18 \\
\hline 12 & 18.5 & 20.1 & 21.2 \\
\hline 12 & 18.52 & 20.11 & 21.2 \\
\hline Mean of multiple measurements, ${ }^{\circ} \mathrm{C}$ & 18.52833 & 20.13167 & 21.205 \\
\hline Standard type A uncertainty, ${ }^{\circ} \mathrm{C}$ & 0.01078 & 0.00946 & 0.00885 \\
\hline 16 & 18.3 & 19.04 & 20.17 \\
\hline 16 & 18.7 & 19.04 & 20.12 \\
\hline 16 & 17.2 & 19.07 & 20.1 \\
\hline 16 & 17.9 & 19.09 & 20.19 \\
\hline 16 & 18.4 & 19.09 & 20.1 \\
\hline 16 & 17.7 & 19.09 & 20.11 \\
\hline Mean of multiple measurements, ${ }^{\circ} \mathrm{C}$ & 18.03333 & 19.07 & 20.13167 \\
\hline Standard type A uncertainty, ${ }^{0} \mathrm{C}$ & 0.22161 & 0.01 & 0.01579 \\
\hline
\end{tabular}

The CPS for vegetable cultivation must maintain the specified modes while operating regardless of the impacts on it. The latter can be achieved in control systems resistant to perturbations. It means that small changes in the input signal or any perturbation, initial conditions or parameters would not lead to significant deviations of the output signal. The considered CPS with the temperature-humidityinsolation control yields 3 conjugated subsystems. Each one is equipped with one or more smart sensors and smart actuators relating to a certain physical quantity. 


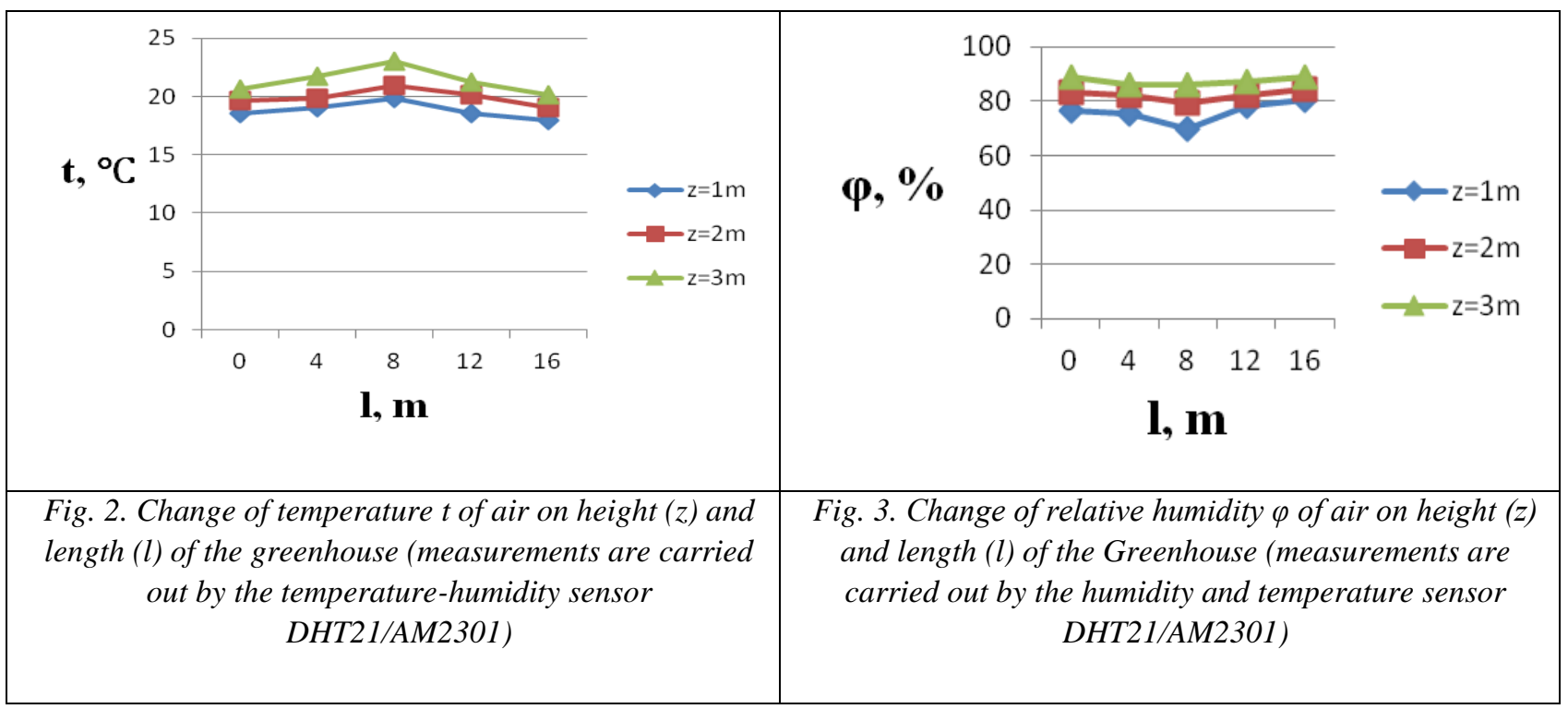

Table 3

The results of repeated measurements of relative humidity on the height and length of the greenhouse by the temperature-humidity DHT21/AM2301 sensor

\begin{tabular}{|c|c|c|c|}
\hline \multirow{2}{*}{ Length, $\mathrm{m} \backslash$ Height, $\mathrm{m}$} & \multicolumn{3}{|c|}{ Relative humidity in the greenhouse, $\%$} \\
\cline { 2 - 4 } & & 2 & 3 \\
\hline 0 & 76.65114 & 83.3241 & 88.62311 \\
\hline Mean of multiple measurements $\varphi, \%$ & 0.01125 & 0.01022 & 0.01232 \\
\hline Standard type A uncertainty, $\%$ & & & \\
\hline 4 & 75.32428 & 81.97186 & 85.96393 \\
\hline Mean of multiple measurements $\varphi, \%$ & 0.00999 & 0.00880 & 0.01010 \\
\hline Standard type A uncertainty, $\%$ & & & \\
\hline 8 & 70.11632 & 79.31843 & 85.96289 \\
\hline Mean of multiple measurements $\varphi, \%$ & 0.00703 & 0.00477 & 0.00749 \\
\hline Standard type A uncertainty, $\%$ & & & 87.29184 \\
\hline 12 & 77.98395 & 81.97106 & 0.00885 \\
\hline Mean of multiple measurements $\varphi, \%$ & 0.01077 & 0.00946 & \\
\hline Standard type A uncertainty, $\%$ & & & 88.62147 \\
\hline 16 & 80.64429 & 84.63285 & 0.01579 \\
\hline Mean of multiple measurements $\varphi, \%$ & 0.22161 & 0.01 & \\
\hline Standard type A uncertainty, $\%$ & &
\end{tabular}

Similar measurements have been made for the relative humidity with the help of the same sensors (Table 3).

As a result of the study, we justified the choice of smart sensors and their mounting places in the greenhouse. The control function can be provided by the PID controllers, the main task of which are temperature, humidity, and insolation control with minimal error relative to the set mode. The PID controller generates an output control signal, which is fed to the actuators. As a result, the heating element begins to heat or the fan - to cool, the shader changes the insolation mode, and the drip humidification system starts to operate.
To substantiate the parameters of the automatic control system, the modeling of thermal processes dynamics using the equations of heat balance has been considered. The statistical error of air temperature regulation does not exceed $\pm 1^{\circ} \mathrm{C}$ at the error of measuring mean readouts, not higher $\pm 0.5^{\circ} \mathrm{C}$, the relative humidity of the air $-3.5 \%$, that is that which lies within a zone of the sensitivity of this mean.

\subsection{Design of the CPS's for the plant} cultivation

Based on the conducted researches the urgency of development of cyber-physical system of cultivation of 
vegetables with the regulation of a heat-moistureinsolation mode is substantiated. It is established that the main information parameters of the microclimate of greenhouses are: air temperature, relative humidity, illumination of the greenhouse, soil temperature, soil moisture, carbon dioxide concentration in the greenhouse. Based on the analysis of technical characteristics of sensors and research with them, the following sensors of cyber-physical vegetable growing system were selected: temperature and humidity sensor (DHT21 / AM2301 and DHT22 - digital sensors with high accuracy with capacitive humidity sensor and NTC thermistor), greenhouse light sensor (BH1750), soil temperature sensor (DS18B20) and capacitive soil moisture sensor (not susceptible to corrosion and therefore independent of soil salinity), sensor greenhouse gas concentration (MHZ19B). The Arduino Uno board, which is a device based on the ATmega328 microcontroller and can smoothly regulate temperature and humidity while maintaining sufficient accuracy of the supported parameters, was used to design a cyber-physical system for growing vegetables. A working model was made and tested. To assess the uniformity of the temperature in the greenhouse and the choice of the location of the device sensors, the temperature and humidity were measured in a stabilized mode. Metrological characteristics of temperature and humidity measurements are studied. The center of the greenhouse was chosen for the installation of measuring sensors. The height of placement is determined by the position of point $A(Z=2 \mathrm{~m})$, in which the average relative to the limit deviations of the devices were recorded. To substantiate the parameters of the automatic control system for growing vegetables, we use mathematical and computer modeling of the dynamics of thermal processes using the equations of heat balance. The control function is provided by the PID controller, the main task of which is to regulate temperature, humidity, insolation with minimal error relative to the set mode. The PID controller generates output control signals.

\section{Conclusion}

Based on the conducted research, the urgency of the development of CPS plant cultivation with the regulation of a temperature-moisture-insolation mode is substantiated. Usually, the CPS's vegetable cultivation necessitates 2 control subsystems that are the systems of the air temperature-control and the relative humiditycontrol in a confined space of Greenhouse. These subsystems determine the soil moisture in it. The most effectively seems to implement additional the 3rd soil moisture-control subsystem as a corrective one. As our studies have proved, the accuracy of the temperature maintaining has not exceeded $\pm 1^{\circ} \mathrm{C}$ and of the humidity $- \pm 3.5 \%$.

\section{Acknowledgments}

The authors express their gratitude to the staff of the Department of Information and Measurement Technologies of the Lviv Polytechnic National University, Ukraine, for the assistance provided and full assistance in the preparation of this article.

\section{Conflict of Interests}

The authors declare that there is no financial or other possible conflict regarding the work.

\section{References}

[1] URL: http://www.fito-system.ru/teplichnoe-oborudovanie

[2] URL: https://arduino.ua/prod1683-datchik-vlajnosti-itemperatyri-dht21am 2301

[3] URL: https://3d-diy.ru/wiki/arduino-datchiki/datchikvlazhnosti-i-temperatury-dht11/

[4] URL: https://arduinka.biz.ua/uk/datchik-osvitlenostiGy-302-bh1750-tsifroviy-p341c74.html

[5] URL: http://mypractic.ru/ds18b20-datchiktemperatury-s-interfejsom-1-wire-opisanie-na-russkomyazyke.html

[6] URL: https://wiki.iarduino.ru/page/capacitive-soilmoisture-sensor/

[7] URL: https://iarduino.ru/shop/Sensory-Datchiki/ datchik-vlazhnosti-pochvy-emkostnoy.html

[8] URL: https://arduino.ua/prod775-datchik-co2

[9] URL: https://arduino.ua/prod1532-datchik-co2-mh-z19

[10] URL: http://www.fito-system.ru/datchik-co2

[11] Основи мікропроцесорної техніки. - Лабораторний практикум / В.С.Баран, Г.Г.Власюк, Ю.О.Оникієнко, О.І.Смоленська URL: https://ela.kpi.ua/bitstream/123456789/ 27992/1/OMPT_laboratorni.pdf 